\title{
Oportunidades existentes para proyectos de intervención socio-educativa en Nicaragua
}

\author{
Ana Teodora Tellez ${ }^{1}$
}

Considero que Nicaragua en los últimos treinta años ha cambiado sustancialmente en los diferentes ámbitos: social, económica, política, ecológica y espiritualmente. El período del neoliberalismo, del capitalismo salvaje, de los años 90 y parte de los 2000 sólo favorecía a la clase empresarial, pues su economía estaba pensada para hacer más pobres a los pobres y más ricos a los ricos.

Ese cambio tan necesario se debe a la voluntad política de nuestro Gobierno de Reconciliación y Unidad Nacional, del FSLN, cuyo proyecto político cristiano, socialista y solidario, está sustentado en valores de cara a la restitución de los derechos y al fortalecimiento de capacidades, a fin de revertir los niveles de pobreza en que está sumida nuestra población.

Es así como, nuestro gobierno ha venido creando condiciones favorables para el desarrollo integral del país. Uno de los factores que ha ayudado mucho, en este sentido, es la participación de Nicaragua como miembro del bloque de países que integran la Alternativa Bolivariana para las Américas (ALBA). Ello ha favorecido el impulso de programas y proyectos dirigidos a todos los sectores, incluido el educativo. En este último, se reflejan mayores facilidades y oportunidades para la planificación y ejecución de proyectos de intervención socio-educativa.

Un ejemplo de lo expresado anteriormente, es el del programa amor para los más chiquitos y chiquitas. Esta estrategia socio-educativa dirigida a las madres y padres de familias tiene como objetivo fortalecer sus conocimientos sobre el cuido de sus hijos e hijas, desde la gestación hasta los seis años de edad.

De igual forma, ha sido posible la intervención socioeducativa a nivel de todos los subsistemas educativos, teniendo como finalidad una mayor incidencia en la solución de problemas sociales y ambientales. Entre éstos destacan: programas de educación ambiental (manejo de agua, residuos sólidos y líquidos, tabaquismo), saneamiento ambiental, campaña de reforestación nacional, violencia intrafamiliar y seguridad alimentaria nutricional. Además, en la educación inicial y primaria se cuenta con el programa de nutrición escolar.

Así mismo, el Ministerio de Educación (MINED) cuenta con el Plan Estratégico de Educación para el quinquenio 2011-2015. El mismo tiene como finalidad, el direccionamiento e implementación de políticas orientadas a una transformación educativa integral. Éste está enfocado al desarrollo de la educación como un derecho humano fundamental, inclusivo y articulado, que busca superar los vicios del modelo aplicado por los gobiernos neoliberales.

1 Estudiante de Doctorado en Educación e Intervención Social en UNAN-Managua. Correo Electrónico: ana.tellezf@yahoo.com 
En lo que concierne a la educación superior, especialmente en las universidades estatales beneficiarias del $6 \%$, se cuenta con mayores facilidades y oportunidades para el desarrollo de proyectos de intervención socioeducativa. Esto se ve favorecido por las relaciones interinstitucionales, con otras universidades, tanto a nivel nacional como internacional, así como con el sector empresarial. Todo ello, como producto de las políticas articuladoras impulsadas por el gobierno revolucionario y sobre todo por su voluntad política de realizar las transformaciones necesarias, que aseguren el bienestar de todas y todos los nicaragüenses.

También esto se enmarca en los objetivos del milenio, pues se ha mencionado que el siglo XXI, es el siglo del conocimiento, o más bien, de la educación, una educación inclusiva, una educación para la democracia, una educación para la libertad y para la sostenibilidad.

Lo anteriormente expuesto, configura escenarios más favorables en donde se presentan más facilidades y oportunidades para que la universidad formule y ejecute programas, proyectos y acciones de intervención socioeducativa; con miras a aportar a la solución de problemas socioeconómicos y socioambientales.

En este nuevo contexto, la Facultad Regional Multidisciplinaria (FAREM) Estelí, UNAN-Managua, viene impulsando una serie de proyectos de intervención socioeducativa. Entre éstos se destacan, la universidad en el campo, el desarrollo de programas a nivel de pregrado y postgrado dirigido al desarrollo de capacidades en organizaciones o instituciones del estado implicadas en la gestión integral de riesgo y cambio climático con enfoque de género y gobernabilidad.

Además, se han realizado acciones de educación ambiental dirigida a grupos de estudiantes de primaria, secundaria y universidades privadas. Se ha participado en campañas educativas a nivel de la comunidad relacionadas con el saneamiento ambiental para la conservación del entorno y disminución de la vulnerabilidad frente a los riesgos de contaminación.

Y por último, considero importante mencionar el énfasis que la universidad le está imprimiendo al eje de investigación en el área socioeducativa y socioambiental, incidiendo de esta manera en la solución de problemas concretos con miras al desarrollo integral de la nación. Esto en la búsqueda de la superación de la dependencia científica y tecnológica, para alcanzar un desarrollo económico con equidad social, justicia social, y respeto al medio ambiente.

\section{BIBLIOGRAFÍA}

GobiernodeReconciliaciónyUnidadNacionalUnidaNicaraguaTriunfa(2011)PolíticaNacionaldePrimera Infancia Amor por los más Chiquitos y Chiquitas. Recuperado de http://www.mined.gob.ni/index. php?option=com_content\&view=article\&id=667\%3Achiquits\&catid=96\%3Avarios\&Itemid=55.

MINED (2011) Plan Estratégico de Educación 2011-2015. Recuperado de http://www.mined.gob.ni/ Documents/Document/2013/pee2011_2015.pdf.

Murillo, R (2013). Los nuevos tiempos. Managua: Consejo de Comunicación y Ciudadanía. 